Esta revista forma parte del acervo de la Biblioteca Jurídica Virtual del Instituto de Investigaciones Jurídicas de la UNAM

\title{
LA SEGURIDAD JURÍDICA EN LA LEY TRIBUTARIA COLOMBIANA*
}

\author{
LEGAL SECURITY IN THE COLOMBIAN TAX LAW
}

\section{Lucía del Carmen Bolaños Bolaños**}

RESUMEN: El presente artículo busca evidenciar la problemática actual del sistema tributario colombiano en perspectiva de la seguridad jurídica y la ley tributaria; para ello se parte del principio de justicia como una orientación natural del derecho tributario, los principios que enmarcan la legalidad y la seguridad jurídica para la configuración de la ley tributaria, analizando la jurisprudencia para finalizar con la exposición del caso colombiano su excesiva producción normativa, las reformas tributarias constantes y la disparidad a efectos tributarios generada por el marco de regulación contable vigente, dejando en evidencia la ardua tarea que debe emprender el país para corregir estos defectos jurídicos y lograr un sistema jurídico tributario más equitativo y justo.

Palabras clave: seguridad jurídica, justicia, legalidad, regulación contable.
ABSTRACT: This article seeks to highlight the current problems of the Colombian tax system in perspective of legal security and tax law; for this the principle of justice is based as a natural orientation of the Tax Law, the principles that frame the legality and the legal security for the configuration of the tax law, analyzing the jurisprudence to end with the presentation of the Colombian case, its excessive normative production, the constant tax reforms and the disparity for tax effects generated by the current accounting regulation framework, highlighting the arduous task that the country must undertake to correct these legal defects and achieve a more equitable and fair tax legal system.

Keywords: legal certainty, justice, legality, accounting regulation.

* Recibido el 28 de mayo de 2020; aprobado el 18 de enero de 2021.

** ORCID: 0000-0003-1454-4554. Profesora investigadora de la Universidad Libre de Cali; doctora en Derecho por la Universidad Autónoma de Chile; miembro del grupo de investigación de sistemas penitenciarios y carcelarios. Correos electrónicos: luciad.bola nosb@unilibre.edu.co,lucia.bolanos@uautonoma.cl

Boletín Mexicano de Derecho Comparado, nueva serie, año LIV, núm. 160, enero-abril de 2021, pp. 35-60. 
Esta revista forma parte del acervo de la Biblioteca Jurídica Virtual del Instituto de Investigaciones Jurídicas de la UNAM

SUMARIO: I. Introducción. II. La ley tributaria en el Estado social de derecho y la seguridad jurídica. III. La Corte Constitucional y la seguridad jurídica. IV. La seguridad jurídica del sistema tributario colombiano. V. Conclusiones. VI. Bibliografia.

\section{INTRODUCGIÓN}

Como bien lo afirmó el profesor Antonio Enrique Pérez Luño, históricamente la seguridad jurídica ha sido eje e impulsor de la historia jurídica, convirtiéndose en "presupuesto" y "función" indispensable en los ordenamientos jurídicos del Estado de derecho; presupuesto en clave de legalidad positiva propia de los derechos fundamentales, subyacentes del derecho constitucional y, función del derecho, garante de la realización de las libertades (2000, pp. 26-28), consolidándose así, la seguridad jurídica como un valor jurídico ineludible no sólo en el Estado de derecho sino en el Estado social de derecho, en razón del carácter constitucional que le reviste.

Esta seguridad jurídica al ser esencia del Estado social de derecho, tiene alcance a todas las ramas del derecho, y para el caso en análisis del derecho y la ley tributarios. Sin embargo, el sistema jurídico tributario colombiano parece alejarse cada día más de tal anhelo jurídico y se sumerge en la excesiva producción normativa, la complejidad, la inestabilidad y la contrariedad, generando como resultado la inequitativa distribución de la carga tributaria de los contribuyentes.

En este sentido, este artículo busca advertir dicha problemática en el sistema tributario de Colombia y su efecto en la estabilidad, la confianza, la certeza y la justicia misma del sistema; para ello, se parte realizando un análisis de la ley tributaria en el Estado social de derecho, exponiendo algunos planteamientos teóricos y doctrinales, para luego abordar el alcance del concepto desde la perspectiva de la Corte Constitucional, finalizando con el particular caso colombiano y las implicaciones jurídicas que de él se desprenden.

\section{LA LEY TRIBUTARIA EN EL ESTADO SOCIAL DE DERECHO Y LA SEGURIDAD JURÍDICA}

El derecho está connaturalmente orientado hacia lo justo (Karls Larenz, 1985, p. 10), en consecuencia si la Ley es una expresión propia del derecho, 
Esta revista forma parte del acervo de la Biblioteca Jurídica Virtual del Instituto de Investigaciones Jurídicas de la UNAM

deberá albergar justicia, representar justicia e inspirarse en ella; por ende, en cumplimiento de este mandato la generalidad es en esencia el principio inspirador de la ley en el Estado derecho (Gustavo Zagrebelsky, 1995, p. 38), mientras que en el Estado social de derecho la ley se nutre de la desigualdad, en virtud del desarrollo del principio de igualdad diferenciada, lo que rompe con el principio de generalidad y la abstracción normativa.

De este modo, la construcción de leyes en el Estado social de derecho, se recrea en la heterogeneidad de contenido, en razón de los diversos intereses de los grupos sociales y las distintas fuerzas de poder que se entretejen en una amalgama de particularidades sectoriales e individuales, a los que la ley se ha moldeado y trata de dar respuesta en equidad y justicia; en consecuencia, la Ley "no es una garantía absoluta de estabilidad" (Gustavo Zagrebelsky, 1995, p. 29) es más bien, un instrumento de la inseguridad jurídica vía configuración o interpretación en el sentido ampliamente expuesto por los profesores Jorge Streeter, Gustavo Zagrebelsky, Andrés Botero Bernal, Mario Fernando Quinche Ramírez, entre otros; y este parece ser particularmente el caso de la ley tributaria en Colombia.

La ley tributaria para el profesor Jorge Streeter, es una norma específica a la que llama secundaria; en tanto, bajo determinadas circunstancias ordena una conducta o prestación "tributo" de un sujeto pasivo a otro sujeto denominado activo (1968, pp. 7-76), bajo la estricta observancia del principio inglés introducido en la carta magna de 1215 no taxation without representation, exigiendo que no exista tributo sin representación y el principio de legalidad fundado en el aforismo nullum tributum sine lege; en virtud de ambos, debe mediar un acto legislativo en la creación de todo tributo, definiendo claramente sus elementos: i) qué situaciones lo originan "hecho generador"; ii) sobre qué cuantía recaerá el tributo "base imponible", iii) qué porcentual o cuantía será aplicable "tarifa", iv) quién es el sujeto obligado "sujeto pasivo", y a v) quién se le debe "sujeto activo"; elementos que teóricamente concretan los principios de legalidad y seguridad jurídica tributaria, en sentido estricto.

Esta tipología de la ley tributaria y sus condicionantes, es el modelo que ha acogido Colombia instituyéndolo en el artículo 338 de la Constitución Política $(\mathrm{CP})$, reservando en tiempos de paz, la competencia legal para el establecimiento de contribuciones fiscales y parafiscales al Congreso, las asambleas departamentales y los concejos municipales; a la vez que ordena que cualquiera que sea el tipo de contribución, su aplicación 
Esta revista forma parte del acervo de la Biblioteca Jurídica Virtual del Instituto de Investigaciones Jurídicas de la UNAM

se hará a partir del periodo que comiencen después de iniciar la vigencia de la ley, la ordenanza o el acuerdo, prohibiendo taxativamente la retroactividad de la norma tributaria en el artículo 363 constitucional.

Así expuesta, la ley tributaria, regula la relación jurídica tributaria originada en virtud de los supuestos de hecho descritos explícitamente en la ley, en razón de ello, lo que debe buscar el intérprete de la norma tributaria ha de ser el significado de la misma dentro de esa específica relación y sus antecedentes, que Jorge Streeter precisa en: i) hecho imponible objetivo y subjetivo, ii) sujetos de la obligación, iii) objeto de la prestación impositiva, iv) modos de extinguir la obligación tributaria, y v) obligaciones formales o accesorias (1968, pp. 12-14). En consecuencia, como bien lo expone el autor, la interpretación de la ley demanda el conocimiento no sólo de la ley tributaria y lo que ella ordena, sino la peculiar relación jurídica que trata de regular, desde su nacimiento hasta su extinción, entiéndase sus elementos y su interrelación.

Pero como se ha expuesto, en el Estado de derecho y más aún en un Estado social de derecho como el colombiano, la realidad es mucho más compleja y desborda la norma; así, el alcance de la norma a los hechos es manifiestamente insuficiente; fenómeno que se presenta no sólo en el derecho tributario, sino en todas las ramas del derecho; situación que teóricamente podría señalarse como la causante de la superproducción normativa, existirán tantas normas como tantas realidades existan.

Desde aquí, para tratar de dar explicación y atribuir la responsabilidad por la inseguridad jurídica, entre disensos y consensos ha transitado la teoría. Algunos, atribuyen la responsabilidad al Congreso y al Ejecutivo, como agentes productores de inseguridad (Mario Fernando Quinche, 2010, p. 122), otros responsabilizan a las cortes de cierre, en tanto les reviste la facultad de hacer y rehacer el derecho vía interpretativa (Javier Tamayo, 2006, p. 396), o cambiando incluso la CP por la aplicación de la doctrina de la sustitución o por la inconstitucionalidad por sustitución (Diego Mauricio Higuera, 2016, p. 215), y otro sector asegura que la misma ley origina la inseguridad, vía lagunas, omisiones, complejidades que entran a ser corregidas por la jurisprudencia y la línea jurisprudencial, en tanto se producen subreglas de derecho que han de servir como reglas de conducta y estándar de crítica a la actividad del administrador de justicia (Diego Eduardo López Medina, 2010, pp. 140 y 141). 
Esta revista forma parte del acervo de la Biblioteca Jurídica Virtual del Instituto de Investigaciones Jurídicas de la UNAM

De esta suerte, lo cierto es que la inseguridad no estriba en las complejas relaciones humanas que la norma pretende regular y que sin importar el origen o los responsables, Colombia es un Estado que soporta una especie de superinflación normativa, que acrecienta la inseguridad jurídica del sistema, ocasionándose la ruptura de las fuentes del derecho, los principios de certeza, confianza legítima, buena fe e igualdad; en suma, es una fisuración del principio de seguridad jurídica del derecho, fenómeno que se siente con mayor rigor en materia jurídico tributaria, como se verá más adelante.

Preliminarmente, se coincide con el profesor Mario Fernando Quinche Ramírez, pues se cree que de una parte, es en el órgano legislativo, la ausencia de técnica y método para la elaboración de proyectos de ley (2010, p. 122), su presentación y aprobación con fundamento en razón jurídica social, cultural, política, financiera y económica de manera proporcionada y pertinente, con visión de prospectiva y no cortoplacista, reconociendo el arraigo en lo nacional pero con la mirada erguida en el contexto universal; lo que sin duda lleva a la promulgación de múltiples y variadas leyes de corto alcance en tiempo y en espacio, oscuras, con vacíos normativos y hasta contradictorias; de otra parte, está el órgano ejecutivo, que ante la complejidad de las leyes, hace uso de diversos decretos que tratan de dar alcance a la norma, en algunos casos sin conseguirlo, enrareciendo más el universo jurídico y ocasionando inestabilidad.

Cualquiera que fuera el caso, en Colombia la configuración de leyes está a la orden del día, parece que se padeciera una suerte de "síndrome normativo" (Andrés Botero Bernal, 2010, pp. 13-21), se producen tantas normas y a tal grado, que día a día los códigos son acrecentados por las abultadas adiciones normativas de cada periodo.

Por ejemplo, en materia tributaria desde el 2005 hasta hoy se pueden mencionar algunas de ellas: Ley 863 de 2003 teóricamente orientada a estimular el crecimiento económico y saneamiento de las finanzas públicas; Ley 1111 de 2006 que reformó la renta, el IVA, el impuesto al patrimonio, la renta presuntiva, el impuesto de timbre, el impuesto a las remesas y transformó algunos apartes de procedimiento tributario, ley modificada parcialmente por la Ley 1151 de 2007 por medio de la cual se expidió el Plan Nacional de Desarrollo; la Ley 1370 de 2009 por la cual se modificó el impuesto al patrimonio, Ley 1429 de 2010 focalizada en la formalización y generación de empleo por medio de una serie de estímulos 
Esta revista forma parte del acervo de la Biblioteca Jurídica Virtual del Instituto de Investigaciones Jurídicas de la UNAM

tributarios, Ley 1430 de 2010 reforma planteada para el control y la competitividad, Ley 1607 de 2012 reforma completa del sistema tributario; ${ }^{1}$ Ley 1739 de 2014 presentada como un mecanismo de lucha contra la evasión, Ley 1819 de 2016 cuya pretensión se fundamentó en una reforma estructural aunado a combatir la evasión y la elusión; Ley 1943 de 2018 mal llamada ley de financiamiento y de equilibrio presupuestal y, la actual Ley 2010 de 2019 que se denominó Ley de crecimiento económico, empleo, inversión, fortalecimiento de las finanzas públicas, progresividad, equidad y eficiencia del sistema tributario, disposición, que se distanció ampliamente de su tan prominente título, esta mención genérica de algunas normas tributarias deja en evidencia que en Colombia, la única constante en el sistema jurídico tributario, es el cambio.

\section{LA GORTE CONSTITUCIONAL Y LA SEGURIDAD JURÍDiCA}

La Corte Constitucional ha identificado en la seguridad jurídica dos dimensiones: i) la dimensión objetiva, cuyo cimiento se encuentra en el artículo 83 de la CP y el principio de buena fe relacionado estrechamente con la confianza legítima; ordenando al administrador de justicia actuaciones con fundamento jurídico, coherentes, estables y consistentes a las circunstancias de cada caso, proscribiendo la contrariedad y protegiendo las expectativas legítimas de las personas sobre las decisiones judiciales su razonabilidad, consistencia y uniformidad (Sentencia C 284/2015), y ii) la dimensión subjetiva, inherente a la certeza que se acuña en la seguridad, relacionada directamente con las esperanzas legítimas de los administrados, que ante casos idénticos se interprete y aplique la ley de forma igual, ${ }^{2}$ son las expectativas de la persona frente sus derechos y obligaciones en razón de sus acciones.

1 Esta ley fue objeto de una serie de decretos reglamentarios, debido a la complejidad normativa y la ausencia de claridad en cuanto al alcance de algunas categorías conceptuales para la determinación de los sujetos obligados, el hecho generador, la base y la tarifa aplicable a cada caso; entre ellos, Decreto: 2763/2012, 2634/2012 0099/2013, 0187/2013, 0568/2013, 862/2013, 1244/2013, 1694/2013, 1793/2013, 1828/2013, 1848/2013,2418/2013, 2701/2013, 3033/2013.

2 La identificación de estas dos dimensiones, la expone de manera general pero clara (Jorge Zavala Egas, 2010, p. 220). 
Esta revista forma parte del acervo de la Biblioteca Jurídica Virtual del Instituto de Investigaciones Jurídicas de la UNAM

En este sentido, en reciente jurisprudencia la Corte Constitucional recordó que la seguridad jurídica es una condición necesaria para la materialización de un orden justo y la concreción de los derechos y libertades de los ciudadanos; pues su cumplimiento representa una garantía para identificar aquello que es ordenado, prohibido y permitido en el ordenamiento jurídico (Sentencia SU-072/2018); por ende, la seguridad jurídica es un sustrato de la justicia y la igualdad, que exige que en un Estado social de derecho la seguridad jurídica vaya más allá de la estabilidad de la ley en el territorio y en el tiempo; pues la estabilidad en sí misma, debe obrar como una garantía jurídica en la interpretación y aplicación de la ley para los administrados (Sentencia SU-337/2017).

De este modo, en virtud del principio de seguridad jurídica, objetivamente es un mandato constitucional, legal e institucional que conmina al administrador de justicia que ante la identidad de circunstancias fácticas, determine las leyes aplicables, las interprete y reconozca los mismos derechos y obligaciones, y subjetivamente es una garantía para que el sujeto de derechos acuñe expectativas ciertas, sobre las consecuencias jurídicas que han de tener sus actuaciones en el ordenamiento jurídico al que él se encuentra obligado.

De otra parte, la Corte Constitucional también señaló los instrumentos para la preservación de la seguridad jurídica: i) la CP, al ordenar mediante el artículo 230 el sometimiento de los jueces al imperio de la ley, ii) la ley, con alcance a los criterios de interpretación y aplicación de la ley, iii) la unificación de jurisprudencia, por medio de la cual se precisa con autoridad y vocación de generalidad el significado y alcance de las diferentes áreas del ordenamiento jurídico, $i v)$ la doctrina y el precedente judicial vinculante, la primera como simple criterio orientador y la segunda como criterio vinculante, garante de la estabilidad de las decisiones y reglas judiciales establecidas con autoridad, v) el Código de Procedimiento Administrativo y Contencioso Administrativo (CPACA), y en concreto los artículos 10 y 102 orientados a asegurar la eficacia de la jurisprudencia unificada y aplicada por extensión (Sentencia C-284/2015).

En este sentido la Corte Constitucional hacia febrero de 2015, ya se había pronunciado reiterando la línea anterior y unificando la jurisprudencia, al analizar la procedencia del control judicial vía tutela sobre providencias que vulneraran los derechos fundamentales. La Corporación en su examen, recordó el carácter ineludible de la unificación de jurispru- 
Esta revista forma parte del acervo de la Biblioteca Jurídica Virtual del Instituto de Investigaciones Jurídicas de la UNAM

dencia, como una herramienta para hacer frente a la disparidad semántica de las normas y reglas jurídicas, dada la ambigüedad del lenguaje y vacíos que dan lugar a múltiples interpretaciones o significados (Sentencia C-053/2015); por lo cual, la unificación de jurisprudencia permitía la determinación de reglas y subreglas de derecho de obligatoria observancia para el operador judicial, para casos en los cuales se presente la similitud de las circunstancias fácticas y tengan cabida la aplicación de las mismas normas de derecho.

De este modo la Corte Constitucional dio alcance a la providencia de 2011, que ordenó la unificación y extensión de la jurisprudencia en las actuaciones judiciales y administrativas, en virtud del derecho de igualdad ordenado en el artículo 13 constitucional y la efectiva protección y mismo trato de los administrados, a fin de garantizar la efectividad de los derechos, la buena fe, la coherencia del orden jurídico, en tanto y en cuanto, a todas las personas les revista el derecho de exigir al administrador de justicia, que en su ejercicio reconozcan los mismos derechos a quienes de hallen en una misma situación de hecho prevista en la ley (Sentencia C-816/2011).

\section{LA SEGURIDAD JURÍDICA \\ EN EL SISTEMA TRIBUTARIO COLOMBIANO}

El estudio preliminar del universo del derecho tributario colombiano permite afirmar que el sistema tributario puede juzgarse como uno de los mayores exponentes del fenómeno jurídico de implosión normativa; la evidencia de ello, en un estatuto tributario abultado, contentivo de normas oscuras, contradictorias, complejas, que dejan en evidencia palmaria los defectos que le acompasan.

El ejemplo más reciente (sin ser el único), menos que vergonzoso para la comunidad jurídica nacional e internacional, lo acaecido con Ley 1943 de 2018 conocida como Ley de Financiamiento.

En este punto es preciso aclarar el contexto en el cual se generó la anecdótica situación, que denota la inseguridad jurídica derivada en los dos órganos del poder: el órgano ejecutivo y el legislativo. En Colom- 
Esta revista forma parte del acervo de la Biblioteca Jurídica Virtual del Instituto de Investigaciones Jurídicas de la UNAM

bia, los periodos presidenciales son de cuatro años sin reelección, ${ }^{3}$ donde el Estado está a cargo de la dirección de la economía (CP, art. 333) y el presidente como dirigente del Estado debe diseñar un Plan Nacional de Desarrollo (PND), que en una parte general describe todos los planes, programas y proyectos que espera ejecutar en el cuatrienio, y en la otra parte, detalla los presupuestos plurianuales que soportan el plan de inversiones y gastos, especificando los recursos necesarios para la ejecución; todo dentro de un marco de sostenibilidad fiscal (EOP 111, 1996); por lo cual, es un deber presentar balanceados los presupuestos, en una correspondencia entre ingresos, gastos e inversión.

El equilibrio presupuestal, obedece a que en Colombia, la ejecución del presupuesto financiero históricamente ha sido deficitario; desde 1898 el gobierno ha tenido que lidiar con la insuficiencia de ingresos para solventar los gastos e inversión estatal (Roberto Junguito y Hernán Rincón, 2004, pp. 1-160), desbalance que con menor o mayor deterioro se ha mantenido y en 2018 llegó a 27 billones equivalentes al 2.23\% del PIB (MinHacienda, 2020). Por esta razón, es una práctica común que, al tenor de las necesidades financieras de cada cuatrienio, el gobierno de turno expida una serie de normas orientadas a la consecución de los recursos que le hagan falta, y ha sido mucho más habitual que la solución sea la emisión de leyes tributarias que cambian total o parcialmente el sistema tributario, como se advirtió previamente.

En este contexto, el actual presidente Iván Duque Márquez, presentó en el mes de noviembre de 2018 el presupuesto de rentas y recursos de capital para la vigencia 2019, seguidamente en diciembre de 2018 fue presentada la Ley 1943, con la cual el presidente buscó financiar los planes de inversión y funcionamiento del PND; sin embargo, varios fueron los problemas que se derivaron de esta habitual práctica colombiana.

De un lado la Ley 1943, que creó, modificó y eliminó impuestos, estableció regímenes especiales, exenciones y modificó tarifas, fue mal llamada Ley de financiamiento para el restablecimiento del equilibrio del presupuesto general y otras disposiciones, negando la naturaleza y la relación

3 Los efectos de la reelección presidencial en Colombia han tenido fuertes defensores y detractores, en virtud de ello, fue prohibida por la CP de 1991, pero el artículo 197 fue reformado y se permitió en el 2004, tras caldeados debates fue nuevamente prohibida en el 2015, al respecto puede verse (Sebastián Rubiano, 2009, pp. 208-247). 
Esta revista forma parte del acervo de la Biblioteca Jurídica Virtual del Instituto de Investigaciones Jurídicas de la UNAM

misma del contenido del lenguaje con las cosas, pues como lo expone Michel Foucault, es la quijotesca imaginación de la semejanza (1971, pp. 53-56), ya que claramente fue una reforma tributaria en sentido extenso; pero éste fue el menor de los problemas, ya que en contra de esta ley se presentaron una serie de demandas, en ejercicio de la acción pública de inconstitucionalidad, tanto por vicios de fondo como de forma. Como resultado el 16 de octubre de 2019 la Corte Constitucional emitió la sentencia en virtud de la demanda de inconstitucionalidad expediente D-13207 por vicios de procedimiento en la formación de la ley.

La alta corporación al someter a análisis los cargos, constató que la ley no cumplió con las reglas de procedimiento, pues omitió la publicidad del texto, con lo cual, se contrariaba el diseño institucional de bicameralismo, se cercenaba la facultad de modificación de las plenarias, se desconocía el rol de las comisiones de conciliación y se eliminaba por completo el sistema de frenos, pesos y contrapesos propio de un Estado social de derecho; magno error, que dejaba sin sustento financiero los planes, proyectos y programas propuestos por el gobierno del presidente Duque. Todo un país en el oscuro y complejo mundo de la incertidumbre financiera, social y empresarial.

Se ha de rescatar que la Corte Constitucional, como supremo intérprete de ley facultada para preservar el orden constitucional, de conformidad con el artículo 241 constitucional, cumplió a cabalidad su función, pues ratificó que la omisión de publicidad generaba invalidez en la deliberación, consentimiento y aprobación del proyecto por parte del Congreso de la República, rompiendo con el principio de consecutividad, y por lo tanto, viciaba insubsanablemente el nacimiento de la ley; pero a la par, dada la gravedad de los efectos de su inconstitucionalidad plena e inmediata, por un lado el Tribunal, otorgó un plazo de un poco más de dos meses para que el ejecutivo y el legislativo, de conformidad con sus competencias en materia tributaria, surtieran el procedimiento para que ratificaran, derogaran, modificaran o presentaran una nueva ley, contentiva de los preceptos normativos declarados inconstitucionales, y por otro, dispuso efectos a futuro a fin de no afectar situaciones jurídicas consolidadas, aunado a la declaración de inexequibilidad diferida (Sentencia C-481/2019), proscribiendo así las reclamaciones por pago de lo no debido a que se vieran tentados a presentar los contribuyentes que en virtud de la Ley 1943 habían cumplido con las obligaciones formales y sustan-

Boletín Mexicano de Derecho Comparado, núm. 160, enero-abril de 2021, pp. 35-60. 
Esta revista forma parte del acervo de la Biblioteca Jurídica Virtual del Instituto de Investigaciones Jurídicas de la UNAM

ciales que en ella se ordenaban; ${ }^{4}$ en todo caso, la plenitud de los efectos empezaría a regir desde el 1o. de enero del 2020.

Difícilmente se puede aludir a un caso similar, en el que las finanzas de un país queden prácticamente en el limbo, a causa del incumplimiento de una de las reglas más básicas de procedimiento en la formación de la ley "la publicidad"; menos aún, uno que da esencia y forma a la democracia representativa y deliberativa propia del modelo de Estado y, es exigida por la tipología de la ley tramitada; en tanto, que como se indicó al inicio, siendo la Ley 1943 una reforma tributaria, esta debía cumplir con los dos principios nucleicos de toda ley tributaria no taxation without representation y nullum tributum sine lege, y ello nunca se dio.

Este ejemplo es uno de los más recientes de los muchos que se podrían recrear y que dan cuenta del síndrome de producción normativa con sus defectos jurídicos asociados, puesto que, primariamente se ocasiona complejidad tributaria vía abundancia, reiteración y hasta contradicción normativa.

Otro de los particulares casos lo ocasionó la Ley 1430 de 2010, que fue objeto de demanda de inconstitucionalidad total, por varios cargos: i) incumplimiento del requisito establecido en el artículo 161 superior, de publicación del informe de conciliación con por lo menos un día de antelación; a la par de ii) ausencia de debate del informe de conciliación; iii) vulneración del artículo 182 del Reglamento del Congreso, Ley 5 de 1992; iv) falta de publicación con un día de antelación y alcance sustancial de la aclaración presentada al informe de conciliación en el procedimiento legislativo; v) ausencia de debate y aprobación por una minoría de la aclaración presentada al informe de conciliación en el procedimiento legislativo de la ley, y vi) vulneración del artículo 187 del Reglamento del Congreso por la conformación de la Comisión Accidental de Conciliación en el trámite de la ley (Sentencia C-076/2012).

La relevancia del caso, está en razón del análisis de los salvamentos de voto que presentaron tres magistrados: María Victoria Calle Correa,

4 La Unidad Administrativa Especial de la Dirección de Impuestos y Aduanas Nacionales (UAE_DIAN), se vio abocada a pronunciarse mediante conceptos de la Subdirección de Gestión Normativa y Doctrina de Bogotá, Resoluciones, para dar claridad al complejo y enrevesado panorama que se enfrentaban los contribuyentes, puede verse: (DIAN, Concepto 100208221-129/2020; DIAN, Resolución 007/2020; DIAN, Resolución 0008/2020; DIAN, Resolución 000042/2020), por mencionar algunos. 
Esta revista forma parte del acervo de la Biblioteca Jurídica Virtual del Instituto de Investigaciones Jurídicas de la UNAM

Jorge Iván Palacio Palacio y Nilson Pinilla Pinilla, quienes se distanciaron de la decisión del colegiado de desestimar los cargos y declarar exequible la ley acusada; pues a juicio de los magistrados, se debió declarar fundados los cargos y consecuentemente declarar inexequible la disposición demandada, posición que se comparte, dada la pertinencia e idoneidad de los argumentos expuestos.

Los magistrados en su análisis, encuentran de una parte, que la Corte Constitucional invirtió la carga de la prueba para el demandante, al desconocer la obligación del Congreso de probar que la publicación se realizó en tiempo, e ignorando como prueba la constancia expedida por el subgerente de la Imprenta Nacional sobre la fecha de publicación; de otra, resaltan que la exigencia de publicación con el plazo mínimo de un día de antelación previsto en el artículo 161 constitucional, es garante de una racionalidad mínima en la deliberación y toma de decisiones, que en ningún caso puede tratarse como ritualidad o trámite, puesto que las leyes tributarias y en especial las adversas al contribuyente, deben sujetarse al rigor constitucional como un mandato material de acatamiento por la seguridad que debe regir el funcionamiento de la economía, siguiendo las reglas de juego aunque ellas conduzcan a resultados inesperados, ello, dado que en el caso la Ley 1430 se publicó en 2011 y no el Diario Oficial 47.937 del 29 de diciembre de 2010 como señalaba el encabezado de la Ley y que la Corte presumió como veraz, pese a que la certificación de la imprenta señalaba el inicio del proceso de digitación el 30 de diciembre de 2010, con claro desconocimiento de las evidencias, incurriendo en un error de incoherencia, al considerar una parte y no el todo (Sentencia C-076/2012).

Los magistrados hacen alusión a dos principios a saber: i) las dudas deben resolverse en favor del legislador y ii) en caso de duda debe resolverse más bien contra el fisco, a los que la Corte debió recurrir sopesándolos para dar solución al caso, considerando que la ley ocasionaba efectos adversos al contribuyente y, no acudir como lo hizo, a una ficción jurídica, donde la realidad era una, pero se obró sin explicitarlo como si hubiese sido otra, para evitar consecuencias indeseables (Sentencia C-076/2012), como las que se podrían derivar de la declaratoria de inconstitucionalidad de la Ley 1430 de 2010, en cuanto entre otras medidas, se realizaban eliminaciones de beneficios tributarios y se modificaban otros. 
Esta revista forma parte del acervo de la Biblioteca Jurídica Virtual del Instituto de Investigaciones Jurídicas de la UNAM

Tan evidente ha sido dicha problemática y aún lo sigue siendo, que en 2016 en Colombia se realizó un intento de compilación normativa tratando de unificar las disposiciones tributarias vigentes por medio de un Decreto Único de Reglamentación Tributaria ([DUT], Minhacienda, 2016), en un esfuerzo por racionalizar y simplificar el ordenamiento jurídico; pese a ello, lo cierto es que hoy coexisten normas repetitivas, contradictorias e incompletas, que en reversan el sistema tributario, dificultando el entendimiento y aplicación de la ley por parte del contribuyente, enmarañando la administración de justicia tributaria por parte del administrador y obnubilando la interpretación de la ley por parte del legislador, lesionando el principio de justicia tributaria como sustrato de todas las exigencias formales y materiales de esta particular ley.

$\mathrm{Al}$ respecto el profesor Jorge Streeter, señala acertadamente que la ley tributaria, en cuanto origina una obligación de carácter legal, debe enmarcarse en las máximas garantías de la legalidad y la seguridad jurídica $(1968$, p. 11), con alcance a los elementos de la relación tributaria, lo que se entiende como la imperativa observancia del Estado, en cabeza del legislador al momento de configurar la ley, el administrador de justicia en la interpretación y el contribuyente en su aplicación; evidentemente el Estado colombiano es el mejor contra ejemplo de la observancia de los mandatos que se derivan de la seguridad jurídica y sus garantías, en tanto, que los colombianos debieron cumplir con las obligaciones impositivas ordenadas mediante la imaginaria "Ley 1943" hasta la emisión de una nueva ley tributaria, y esto sólo sucedió hasta diciembre de 2019, un año después con la emisión de la Ley 2010 de 2019, reformada versión de la ley de financiamiento, mal llamada por el gobierno ley de promoción del crecimiento económico, el empleo, la inversión de las finanzas públicas y la progresividad, equidad, eficiencia del sistema tributario, afiligranada denominación, que trataba de recubrir el exabrupto jurídico.

En este vaivén de inseguridad jurídica tributaria, por un lado, vía producción normativa, por otro, vía interpretación y aplicación normativa, ha transitado Colombia. Sumado a ello, el hecho de que en Colombia es una constante en el sistema jurídico tributario, que las diversas reformas tributarias se traten de justificar en la consecución de objetivos constitucionalmente relevantes y legítimos, reiterados jurisprudencialmente por la Corte Constitucional y que me permito citar: 
Esta revista forma parte del acervo de la Biblioteca Jurídica Virtual del Instituto de Investigaciones Jurídicas de la UNAM

i) Recuperación y desarrollo de áreas geográficas gravemente deprimidas en razón de desastres naturales o provocados por el hombre; ii) Fortalecimiento patrimonial de empresas o entidades que ofrecen bienes o servicios de gran sensibilidad social; iii) Incremento de la inversión en sectores altamente vinculados a la generación de empleo masivo; iv) Protección de determinados ingresos laborales; v) Protección a los cometidos de la seguridad social; vi) En general, una mejor redistribución de la renta global que ofrece el balance económico del país (Sentencia G-1107/2001).

Sin embargo, la mayoría de los beneficios tributarios establecidos en las reformas tributarias lejos de concretar los fines constitucionales prometidos, han acrecentado la inequitativa distribución de la carga tributaria.

Excepcionalmente, se quedan al margen los beneficios tributarios estipulados en las reformas tributarias promulgadas en favor de la recuperación y desarrollo de áreas geográficas, severamente perjudicadas por desastres naturales; reformas que, en efecto, de alguna manera sí han contribuido en mayor o menor medida al cometido constitucional.

Uno de estos casos, la promulgación de la Ley 218 de 1996, expedida para conseguir la reconstrucción de la región del departamento del Cauca, especialmente la Zona Norte, Popayán, Santander de Quilichao y Caloto, que fueron particularmente afectadas por un terremoto que devastó las zonas, y para ello, por medio de la Ley 218 se establecieron una serie de exenciones tributarias que propiciaron la creación y asentamiento de industrias, de zonas francas, la generación de empleo, el mejoramiento de la infraestructura vial, la infraestructura de los servicios públicos y la dinamización de la economía en general (Centro de Investigaciones en Economía y Finanzas [CIENF], 2008, pp. 99-102); salvo este ejemplo, las demás reformas tributarias en el mejor de los casos no han producido efecto alguno y en casos extremos, lejos de coadyuvar al objetivo constitucional, han acrecentado las situaciones de inequidad e injusticia del sistema tributario; este es el caso, de la Ley 1429 de 2010 que buscó formalizar y generar nuevos empleos en el país, otorgando beneficios tributarios, que sí fueron aprovechados por los empresarios, pero a cambio de una tasa marginal de generación de empleo (Juan Diego Espinel, 2016, p. 40), una relación costo-beneficio negativa para el país; que si bien disminuyó directamente el costo de salarios y prestaciones sociales para los empre- 
Esta revista forma parte del acervo de la Biblioteca Jurídica Virtual del Instituto de Investigaciones Jurídicas de la UNAM

sarios, no generó la tasa de ocupación laboral estimada, y que sí aminoró directamente el recaudo fiscal.

Corroborando lo expuesto, Colombia ha sido catalogado por organismos nacionales e internacionales en diversos informes, como uno de los países de Latinoamérica más inestables en materia jurídico tributaria, con una tasa nominal de tributación elevada para las personas jurídicas, pero que por efectos de la aplicación de los beneficios tributarios la tasa de tributación efectiva es ostensiblemente menor (CEECT, 2015, p. 10) ocasionando que, comparativamente, la tributación real en términos del PIB llegue a un modesto $19.4 \%$ del PIB, 3.7 puntos porcentuales por debajo de la media de Sur América que alcanzó un 23.1\% para el 2018 (OEGD Publishing, 2020, p. 65).

$\mathrm{Al}$ enrarecido universo normativo expuesto de manera general, sobre el cual se cimienta la estructura del sistema tributario colombiano, se sumó la incertidumbre jurídica generada a partir de 2010, en cuanto en 2009 por medio de la Ley 1314 se acogieron los principios y normas de contabilidad e información financiera y aseguramiento de la información, ordenando la implementación de las (otra vez mal llamadas) Normas Internacionales de Información Financiera (NIIF).

Esta dinámica de estandarización internacional de contabilidad en la que entró Colombia desde el 2009 con las NIIF, obedeció a los requerimientos de los organismos multilaterales como la Organización Mundial del Comercio (OMC), la Organización para la Cooperación y Desarrollo Económico (OCDE), el Fondo Monetario Internacional (FMI) y el Banco Mundial (BM); estos dos últimos organismos desde el 2003 promovieron el informe Reports on the Observance of Standards and Codes (ROSG), por el cual se iniciaba el velado proceso de legitimación de un novedoso sistema de representación de la información financiera ajustado a los requerimientos de los grupos empresariales, multinacionales y transnacionales que transaran en bolsa, justificado teóricamente en objetivos de aseguramiento, competitividad, productividad y desarrollo equilibrado de los mercados, con el hipotético supuesto de facilitar el libre y justo intercambio de los mercados.

La adopción de estándares de representación contable para generar información financiera "razonable" a los propósitos de los agentes que cotizaban en bolsa, lejos de generar una pretendida uniformidad, ocasionó una disparidad de la información contable y financiera; puesto que, 
Esta revista forma parte del acervo de la Biblioteca Jurídica Virtual del Instituto de Investigaciones Jurídicas de la UNAM

la aplicación de determinados estándares está mediada por aquello que los agentes establezcan como principios rectores de valoración, medición y representación en las políticas contables; así, en consecuencia dos entes económicos pertenecientes al mismo sector industrial, comercial o de servicios, con similares características podrían llegar a representaciones contables y financieras marcadamente diferentes, en razón de sus políticas.

Pero, además de las disímiles representaciones contables y financieras de entes económicos semejantes, la inseguridad tributaria obedeció principalmente al artículo 4o. de la Ley 1314, que establecía la autonomía de las normas tributarias frente a las nuevas normas de contabilidad y en caso de incompatibilidad entre estas, prevalecería la norma fiscal, generando partidas de conciliación fiscal y extrafiscal, que aún hoy, permanecen en los estados financieros, ocasionando mayor o menor valor en el resultado del ejercicio, fuente de partida para el cálculo de la alícuota impositiva por impuesto de renta y complementarios.

Desde entonces y hasta hoy, se han dado fuertes debates académicos y jurídicos sobre la interpretación del artículo, más aún sobre el alcance del nuevo modelo de las reglas a las cuales debían someterse los empresarios según el grupo al que pertenecieran: grandes empresas, medianas empresas o microempresas.

De otra parte, el cuestionamiento sobre el nuevo marco de regulación contable no fue, ni es de poca monta, ello en cuanto, a que el cuerpo de reglas es producido por un organismo internacional de carácter privado, la International Accounting Standards Board (IASB), que en 2015 estaba conformado por 16 miembros de los cuales $11^{5}$ de ellos eran parte de las grandes firmas de auditoría (Lucía del Carmen Bolaños, 2015, p. 13), organismo que emitió las International Financial Reporting Standards (IFRS); pues bien, el asunto cuestionable se deriva de una pregunta fundamental: ¿cómo es posible que unos estándares construidos, direccionados y de propiedad de una institución de carácter eminentemente privado,

5 Dentro de los once miembros se cuentraban: Ian Mackintosh de Copers \& Lybrand; Philpe Danjou de Arthur Andersen \& Co.; Patrick Finegan de Mody's Investors Service; Prabhakar Kalavacherla de KPMG; Paul Pacter de Deloitte y posteriormente KPMG; Martin Edelman de KPMG y ZEB; Mary Tokar de KPMG; John Smith de Deloitte; Darel Scot de Grupo FirstRand Banca; Takatsugu Ochi de la Corporación de Recursos de Sumitomo; Amaro Luiz de Oliveira Gomes Ex-Jefe del Departamento Financiero del Sistema de Regulación del Banco Central de Brasil; Chungwo Suh de KASB. 
Esta revista forma parte del acervo de la Biblioteca Jurídica Virtual del Instituto de Investigaciones Jurídicas de la UNAM

se acogieran como normas de regulación contable que son de carácter eminentemente público?, es por lo menos en principio una antinomia jurídica.

Me explico, en Colombia, de acuerdo con el artículo 93 constitucional entran a formar parte del sistema jurídico, las normas de carácter internacional en virtud de un convenio, tratado o pacto internacional debidamente firmado, sólo cuando son aprobados por el gobierno y ratificados por el Congreso; sobre los cuales opera el control de constitucionalidad previo y automático (A. Ramelli Arteaga, 2004, pp. 157-175); este no fue el caso de las NIIF; en tanto, estos estándares son emitidos por un organismo de carácter privado y no entraron al ordenamiento en virtud de convenio, tratado o pacto internacional; más aún, todos los derechos sobre este conjunto de estándares, pertenecen al organismo privado que las produce la IASB; pero las normas de carácter contable en Colombia regulan la representación y suministro de información contable y financiera de carácter público, por ende, al menos teóricamente existe una disparidad conceptual, que podría interpretarse como una representación de las palabras sin las cosas.

De este modo, la contabilidad se enfrentó a una transformación conceptual y contextual, aparentemente natural, porque esa simulación de naturalidad la ordena el capital (Lucía del Carmen Bolaños, 2015), situación que vuelve aún más complejo el sistema jurídico tributario; por cuanto, la contabilidad como sistema de información, suministra la materia prima esencial para conocer con mayor grado de precisión el origen o no de la obligación tributaria en el marco de los presupuestos jurídicos definidos por la ley tributaria, para un buen número de personas jurídicas y personas naturales; pero el nuevo sistema de información contable y representación financiera permite el uso de sistemas de medición y valoración disímiles para los agentes económicos, según los métodos definidos en las políticas contables; por ende, un mismo hecho económico puede ser medido, valorado y representado de forma diferente; en consecuencia, si las representaciones de los hechos económicos, de los cuales da cuenta la contabilidad, no son tal, ¿cómo determinar la existencia o inexistencia de la relación jurídico tributaria?, pues también puede ser o no ser.

Este efecto o defecto jurídico, se ha agudizado por otro fenómeno, el de la globalización, como una serie compleja de procesos, que en los ordenamientos jurídicos tiene un efecto bidireccional; por un lado reordena 
Esta revista forma parte del acervo de la Biblioteca Jurídica Virtual del Instituto de Investigaciones Jurídicas de la UNAM

la reconstrucción de paradigmas y, por otro la reorganización de los poderes de los gobiernos; de este modo, paulatinamente se ha ido configurando un orden jurídico supranacional, engendrado por la lógica impuesta por las tecnoestructuras a los diferentes gobiernos (Miguel Carbonell, 2009, p. 22), que demanda la flexibilización, invisibilización o anulación de las fronteras físicas y jurídicas para la movilidad transfronteriza de capitales; ${ }^{6}$ es el frenesí de la globalización en virtud del cual los estados ven limitada y restringida su potestad legislativa tributaria (Marco García, 2014, p. 127), donde la riqueza real queda oculta, las cargas fiscales que recaen sobre los capitales estables y volátiles se disminuyen, incrementando la presión fiscal sobre los rendimientos del trabajo y la propensión al consumo, anulando los principios tradicionales que cimientan la tributación: la justicia, la equidad, la capacidad contributiva y la no confiscatoriedad, generando un nuevo régimen de formación normativa que castra uno de los principios democráticos y de derecho, otrora tan reclamado y defendido por la sociedad "la representación" (Marco García, 2014, pp. 127-131).

En este nuevo orden global, se consolidan instrumentos de regulación teóricamente no vinculantes; pero que superan ampliamente la actividad legislativa (Marco García, 2014, p. 133), ¡la derrumban! Al dar paso a la aplicación de un derecho flexible, dúctil, el llamado soft law, donde la discrecionalidad es la regla y la imperatividad derivada de la precisión de la ley es la excepción; un sombrío panorama donde la soberanía legislativa de los estados se desdibuja ante el poder del mercado internacional, que encuentra el balance de la distribución de la carga tributaria, en una mayor exacción para las personas y la sociedad en general y, una menor para las rentas generadas por capital total o parcialmente internacional, ignorando la razón misma del derecho "la justicia"; sin embargo, su legitimidad no se cuestiona se asume en razón del poder que las origina, tal cual, lo anticipó Ferdinand Lasalle en 1863, es la supremacía de los factores reales y efectivos del poder, hoy ejercida por los mercados internacionales, sobre, como diría el autor, el papel escrito "la norma interna" (1999, p. 62); es sin duda la construcción de un nuevo orden en el mundo,

6 Una de las explicaciones de esta dinámica de acuerdo con Chikin, es la necesaria compensación bilateral en las relaciones económicas internacionales, que difícilmente se pueden incorporar en resoluciones institucionales multipartitas (1989, p. 861). 
Esta revista forma parte del acervo de la Biblioteca Jurídica Virtual del Instituto de Investigaciones Jurídicas de la UNAM

pero sin conocer qué es lo ordenado o qué se está ordenando, ocultando el temor inconsciente generado por la incertidumbre que hay en el fondo (Artur Max Neef, A. Lizalde y M. Hopenayn, 1998, pp. 34 y 35), es una sumisión profunda en la confusión constante de las palabras, reitero, sin las cosas; así, se confunde la sugerencia con la regla y la ley con la justicia.

Es un nuevo orden de las cosas, en una lógica de entrada y salida de capitales, para la ejecución de actividades de producción, industriales, de servicios o repatriación de capitales, que en casos ya conocidos han generado efectos negativos, daños irremediables, puesto que ha de recordarse, por ejemplo, la explotación extensiva de los recursos naturales no renovables como si realmente lo fueran, dejando el rastro del daño ambiental $^{7}$ o ecológico puro (A. Ruda González, 2006), en la mayoría de los casos irreparables.

Así, en esta coyuntura de país, Colombia construye su política fiscal, que podría caracterizarse como reaccionaria; en tanto, da respuestas cortoplacistas a las necesidades financieras de cada cuatrienio, dejando de lado la función redistributiva de la exacción, por lo cual, es políticamente débil la construcción de una Hacienda Pública responsable, exteriorizada en el gasto con calidad; quizá por ello, en ningún gobierno los recursos tributarios recaudados han resultado suficientes para la financiación del gasto y la inversión pública.

Aunado a ello, como ya se mencionó las constantes reformas tributarias por medio de normas inequitativas que poco o nada contribuyen a un sistema tributario justo (Julio Roberto Piza, 2014, pp. 159-166), complejas (David Domínguez, 2014) que afectan la equidad y progresividad del sis-

7 Uno de los casos internacionales que ejemplifica el devastador efecto medioambiental, es la Oroya ubicada en la cordillera central de Perú, que en 2013 contaba con una población de 33.000 habitantes y hoy cuenta con tan sólo 11.000 , siendo calificada como una de las ciudades más contaminadas del mundo, ello debido a la explotación minera de Doe Run Perú (DRP), una filial del grupo estadounidense RENCO. La extracción de DRP desde su inicio generó contaminación al aire con la generación de humo extremadamente tóxico por las emisiones de dióxido de azufre (SO2) plomo, micropartículas, niveles de arsénico y cadmio, lo que dejó un alto grado de intoxicación en la población evidenciado en presencia de plomo en la sangre e intoxicación que es irreversible. A su retiro DRP se declaró ilíquida y entró en proceso de liquidación dejando a la población en mayor abandono y condenada a padecer las secuelas la ejecución irresponsable de una actividad económica contaminante (FIDH, 2013, pp. 6-19).

Esta obra está bajo una Licencia Creative Commons 
Esta revista forma parte del acervo de la Biblioteca Jurídica Virtual del Instituto de Investigaciones Jurídicas de la UNAM

tema (Camilo Francisco Caycedo, 2014, pp. 36-45); en virtud, del establecimiento de un régimen de beneficios tributarios que aumentan el gasto tributario e inclinan la balanza en favor de algunos contribuyentes y en detrimento de muchos otros (Jairo Bautista, 2011, pp. 70-72), ello queda evidenciado en los informes de la UAE_DIAN, desde el 2004 a 2016 donde claramente se puede advertir el efecto del régimen de beneficios tributarios. (Gloria Yori y Enrique Bravo, 2004)

Es realmente un problema de la mayor relevancia; de un lado, un exceso de producción normativa, con reformas constantes de los elementos del tributo y la relación tributaria que subyacen en la ley tributaria; de otro, la interpretación de esa misma ley, que en sede de complejidad normativa conmina al error del legislador en la configuración de la ley, el administrador en la interpretación de la ley y la administración de la justicia en el ámbito tributario, y al contribuyente en la compresión y aplicación de esa ley para la determinación de las obligaciones accesorias y la cuantificación de la alícuota de la obligación sustancial.

Este contexto denota que en Colombia, el sistema jurídico tributario debe ser objeto de un trabajo razonado y concluyente, que simplifique la norma por medio de la unificación de las ya existentes, la claridad de las que puedan llegar y la continuidad de las mismas, sin que ello signifique su invariabilidad; sumado a ello, la invaluable tarea que debería comenzar la Corte Constitucional, en la consolidación de la jurisprudencia para la construcción de líneas jurisprudenciales sólidas, por medio de las sentencias de unificación, que posibiliten que ante la inexistencia de norma, las lagunas normativas u omisiones legislativas, los sujetos de la obligación tributaria cuenten con una herramienta clara en la lectura, entendimiento, interpretación y aplicación de la ley, lo que sin duda contribuiría directamente a la seguridad jurídica tributaria como una de las principales fuentes de la justicia en la relación jurídico tributaria y por tanto en el sistema tributario.

\section{GONCLUSIONES}

Hoy la ley, pese a que debe sujetarse al principio de justicia como sustrato de todas las exigencias formales y materiales que ordena el derecho, se ha convertido en un instrumento de la inseguridad jurídica vía configuración

Esta obra está bajo una Licencia Creative Commons

Atribución-NoComercial-SinDerivar 4.0 Internacional, IIJ-UNAM.

Boletin Mexicano de Derecho Comparado, núm. 160, enero-abril de 2021, pp. 35-60. 
Esta revista forma parte del acervo de la Biblioteca Jurídica Virtual del Instituto de Investigaciones Jurídicas de la UNAM

e interpretación, ello en razón, que en el Estado social de derecho la ley se ha distanciado del principio de generalidad y se ha incrustado en el principio de igualdad diferenciada, en virtud del cual se ha explosionado la emisión de normas específicas para grupos muy particulares.

Históricamente la ley tributaria se ha enmarcado en dos principios nucleicos de la seguridad jurídica, no taxation without representation y nullum tributum sine lege; por ende, no puede ni debe existir impuesto sin representación, deliberación y ley que defina expresamente los elementos del tributo; cualquiera sea el impuesto, está conminado a la inconstitucionalidad si ello no se cumple.

La Corte Constitucional en Colombia, ha dado alcance al concepto de seguridad jurídica vía jurisprudencial, identificando una dimensión objetiva relacionada de manera directa con el artículo 83 de la CP y el principio de buena fe en correspondencia con la confianza legítima, y una dimensión subjetiva, inherente al sujeto de derechos y sus expectativas de previsibilidad de las consecuencias jurídicas derivadas de sus acciones, dentro del ordenamiento jurídico al cual se encuentra obligado. Así, ha ordenado a la jurisdicción ordinaria y administrativa unificar la jurisprudencia, en aras de garantizar que a iguales circunstancias de hecho les sean imputables las mismas consecuencias jurídicas, en cumplimiento en extenso del mandato constitucional de igualdad del artículo 13.

El caso colombiano es en extremo singular, su ordenamiento jurídico tributario se caracteriza por la excesiva emisión normativa aparejada a las necesidades financieras del gobierno de turno; así, se emiten leyes tributarias, que cambian parcial o totalmente el sistema tributario, incluso en el mismo periodo; sumado a ello el reciente régimen contable bajo NIIF por el cual se permite la representación de la información de los hechos económicos de manera diversa a los agentes económicos, por lo cual la información base para la determinación de la alícuota impositiva y algunas obligaciones accesorias, añade incertidumbre, acrecentando la disparidad y consecuentemente la desigualdad jurídico tributaria, pues una norma puede ser interpretada y aplicada en razón de las políticas contables fijadas por cada organización.

De otra parte, Colombia al igual que otros estados latinoamericanos ha acogido los lineamientos de organismos multilaterales como el FMI, el BM, la OCDE, la OMC, cuyas recomendaciones lejos de ser simples sugerencias se han convertido en mandatos obligatorios, regulaciones 
Esta revista forma parte del acervo de la Biblioteca Jurídica Virtual del Instituto de Investigaciones Jurídicas de la UNAM

dúctiles que han dado paso a la discrecionalidad del legislador y el operador jurídico, con claros efectos negativos para el contribuyente, puesto que como se advirtió líneas atrás, el poder que ejercen los mercados internacionales se incrusta en una mayor carga tributaria para la población y una menor carga para los capitales de cuño internacional.

La declaratoria reciente de inconstitucionalidad diferida de la Ley de financiamiento 1943, que era el andamiaje que sostenía todo el PND del actual gobierno del presidente Duque, dejó en evidencia que Colombia es el contraejemplo del cumplimiento de una de las exigencias de la ley tributaria; en tanto que la ley tributaria al dar origen a una obligación de carácter legal debe (tiene) gozar de las máximas garantías de legalidad y seguridad jurídica.

Queda claro que si el gobierno colombiano no corrige la política para la configuración de un sistema jurídico tributario con normas claras, concretas, permanentes pero no perpetuas, difícilmente mejorará su dinámica interna de desarrollo económico y social altamente inequitativo y, por tanto, injusta.

Se cree que una de las alternativas que el gobierno debe explorar y fomentar con mayor rigor, es la consolidación de un órgano especializado en derecho tributario, que opere de manera permanente en varios frentes: i) como un consejo de políticas fiscales de largo plazo, ii) como organismo de carácter técnico compilador de las normas, las que existen y las que puedan llegar, iii) como consejo consultivo y de apoyo a los contribuyentes, iv) como organismo de apoyo en la fiscalización para el cumplimiento de la regulación vigente; pues como se explicó, la inseguridad jurídica es la manifestación de una serie de factores, que deben ser tratados como un todo, pero sin descuidar las partes, que si bien de algún modo se han estudiado en comisiones temporales, como la Comisión de Expertos para la Equidad Tributaria conformada en 2015, su temporalidad rompe con la rigurosidad que demanda este tema fundamental.

\section{BIBLIOGRAFÍA}

Bautista, Jairo Alonso (2011). Equidad o inequidad tributaria: la distribución del impuesto a la renta en Colombia: 1990-2002. Cuadernos de Contabilidad (30). 
Esta revista forma parte del acervo de la Biblioteca Jurídica Virtual del Instituto de Investigaciones Jurídicas de la UNAM

Bolaños Bolaños, Lucía del Carmen (2015). NIIF para PyMes: relación costo beneficio del proceso de adopción y convergencia para las PyMes en Colombia. Encuentro Nacional de Profesores de Contaduría Pública (4).

Botero Bernal, Andrés (2010). Diagnóstico de la eficacia del derecho en Colombia y otros ensayos. Ensayos jurídicos sobre teoría del derecho. Universidad de Buenos Aires. La Ley.

CArbonell, Miguel (2009). Globalización y derecho: algunas coordenadas para el debate". En Miguel CARBOnELL y Rodolfo VÁsQUEZ (coords.), Globalización y derecho. Quito. Ministerio de Justicia y Derechos Humanos.

Caycedo Tribín, Camilo Francisco (2014). Una aproximación a las modificaciones introducidas por la Ley 1607 de 2012 al régimen de las personas jurídicas desde la perspectiva del principio constitucional de eficiencia. Instituto Colombiano de Derecho Tributario (70).

Centro de Investigaciones en Economía y Finanzas Cienfi (2008). 10 años de la Ley Páez. Transformación de la economía caucana. Santiago de Cali. Universidad ICESI.

Chinkin, Christine Mary (1989). The Challenge of Soft Law: Development and Change in International Law. The International and Comparative Law Quarterly, 38(4), pp. 850-866. http://wwwe.jstor.org/stable/759917

Comisión de Expertos para la Equidad y la Competitividad Tributaria (2015). Informe final presentado al Ministerio de Hacienda y Crédito Público. https://www:fedesarrollo.org.co/sites/default/files/LIBAgosto2016Comision. $p d f$

DOMínguez, David (2014). El régimen tributario de las personas naturales después de la Ley 1607 de 2012. Revista de Derecho Privado (70).

ESPINEL PINZÓn, Juan Diego (2016). Evaluación de los resultados de la Ley 1429 de 2010 -De formalización y generación de empleo vista desde los beneficios otorgados en reducción de aportes parafiscales para las pequeñas empresas en la ciudad de Bogotá (tesis de maestría). http://bdigital.unal.edu.co/52426/

Find Information Concerning (2013). Complejo metalúrgico de la Oroya: donde la inversión se protege por encima de los derechos humanos. International Federation for Human Rights. https://wrere.fidh.org/IMG/pdf/informe_la_oroya. $p d f$ 
Esta revista forma parte del acervo de la Biblioteca Jurídica Virtual del Instituto de Investigaciones Jurídicas de la UNAM

Foucault, Michel (1971). Las palabras y las cosas: una arqueología de las ciencias humanas, trad. Elsa Cecilia Frost. Siglo Veintiuno Editores Argentina.

García Bueno, Marco César (2014). El derecho tributario nacional frente a la normativa internacional fiscal: el soft law. En Ríos GRANADOS, Gabriela (coord.), Derechos humanos de los contribuyentes. UNAM, Instituto de Investigaciones Jurídicas.

Higuera Jiménez, Diego Mauricio (2016). Análisis dinámico de la línea jurisprudencial respecto de la sustitución de la Constitución. Revista Principia Iuris (26).

Junguito, Roberto y Rincón, Hernán (2004). La política fiscal en el siglo XX en Colombia. Borradores de Economía (318).

LARENZ, Karls (1985). Derecho justo: fundamentos de ética jurídica, trad. de Luis Diez de Picazo. Civitas.

LASALLE, Ferdinand (1999). ¿Qué es una Constitución? Panamericana. https:// wrere.elaleph.com/

López MedinA, Diego Eduardo (2010). El derecho de los jueces. Universidad de los Andes.

Max NeEF, Artur Manfred, Lizalde, Antonio y Hopenayn, Martín (1998). Desarrollo a escala humana: conceptos, aplicaciones y algunas reflexiones. Icaria Editorial.

Oecd Publishing (2020). Revenue Statistics in Latin America and the Caribbean 1990-2018. Centro de Política y Administración Tributaria OCDE. https://read.oecd-ilibrary.org/taxation/revenue-statistics-in-latin-america-andthe-caribbean-2019_25666b8d-en-es\#page4

PÉREZ LuÑO, Antonio Enrique (2000). La seguridad jurídica: una garantía del derecho y la justicia. Boletín de La Facultad de Derecho (15).

PIZA, Julio Roberto (2014). Equidad y simplicidad en el impuesto a la renta de las personas. Revista de Derecho Fiscal (7).

Quinche RAmíRez, Mario Fernando (2010). La seguridad jurídica frente a las sentencias definitivas. Tutela contra sentencia. Estudios SocioFurídicos (12).

RAMELli ARTEAGA, A. (2004). Sistema de fuentes de derecho internacional público y "bloque de constitucionalidad" en Colombia". Cuestiones Constitucionales (11). 
Esta revista forma parte del acervo de la Biblioteca Jurídica Virtual del Instituto de Investigaciones Jurídicas de la UNAM

Rubiano Galvis, Sebastián (2009). La independencia del Banco de la República y la reelección presidencial. Mayorías sin democracia. Desequilibrio de poderes y Estado de derecho en Colombia. De Justicia.

RUDA GONZÁLEZ, A. (2006). El daño ecológico puro. La responsabilidad civil por el deterioro del medio ambiente (tesis doctoral). https://dugi-doc.udg.edu/bitstream/handle $/ 10256 / 4774 /$ targ.pdf? sequence $=5$ Eis Allowed $=y$

STREETER, Jorge (1968). La interpretación de la Ley Tributaria. Revista de Derecho Económico (21-22).

TAMAYO JARAmiLLO, Javier (2006). El nuevo derecho, el escepticismo ante las normas y el uso alternativo del derecho. Revista Facultad de Derecho y Ciencias Políticas (36).

YORI PARRA, Gloria y Bravo Díaz, Enrique (2004). Los beneficios tributarios en el impuesto sobre la renta en Colombia. Año 2003. Departamento Administrativo Espacial Dirección de Impuestos y Aduanas Nacionales. https:// wrwedian.gov.co/dian/cifras/Cuadernos\%20de\%20Trabajo/Los\%20benefi cios $\% 20$ tributarios $\% 20$ en $\% 20$ el\%2 0 impuesto $\% 20$ sobre $\% 20$ la $\% 2$ renta $\% 20$ en\%20Colombia.\%20A\%C3\%B10\%202003.pdf

Zagrebelsky, Gustavo (1995). El derecho dúctil: ley, derechos y justicia, trad. Marina Gascón. Trotta.

Zavala Egas, Jorge (2010). Teoría de la seguridad jurídica. Iuris Dictio (14).

Leyes, decretos y jurisprudencia

Congreso de la República de Colombia, Decreto 1625, 2016.

Congreso de la República de Colombia, Ley 1943, 2018.

Congreso de la República de Colombia, Ley 1429, 2010.

Congreso de la República de Colombia, Ley 1314, 2009.

Congreso de la República de Colombia, Ley 218,1996.

Constitución Política de Colombia, 1991, Colombia.

Ministerio de Hacienda y Crédito Público, Estatuto Orgánico de Presupuesto, Decreto 111, 1996.

Sentencia C 481/ 2019, Corte Constitucional de Colombia. https://wrere. corteconstitucional.gov.co/Relatoria/2019/C-481-19.htm

Sentencia SU 072/ 2018, Corte Constitucional de Colombia. https:// wrwe.corteconstitucional.gov.co/Relatoria/2018/SU072-18.htm 
Esta revista forma parte del acervo de la Biblioteca Jurídica Virtual del Instituto de Investigaciones Jurídicas de la UNAM

Sentencia SU 337 /2017, Corte Constitucional de Colombia. https://wrere. corteconstitucional.gov.co/Relatoria/2017/SU337-17.htm

Sentencia C 284/2015, Corte Constitucional de Colombia. https://wrwre. corteconstitucional.gov.co/Relatoria/2015/C-284-15.htm

Sentencia C 053/2015, Corte Constitucional de Colombia. https://wrere. corteconstitucional.gov.co/Relatoria/2015/SU053-15.htm

Sentencia C 816/2011, Corte Constitucional de Colombia. https://wrere. corteconstitucional.gov.co/Relatoria/2011/C-816-11.htm

Sentencia C 076/2012, Corte Constitucional de Colombia. https://wrere. corteconstitucional.gov.co/Relatoria/2012/C-076-12.htm

Sentencia C 1107 de 2001, Corte Constitucional de Colombia. https:// wrere.corteconstitucional.gov.co/Relatoria/2001/C-1107-01.htm

Sitios oficiales y páginas web

Ministerio de Hacienda y Crédito Público. Balance Fiscal del Gobierno General (\%) PIB. https://wrere.minhacienda.gov.co/webcenter/portal/Estadisticas/ pages_macroeconomia/balancegobiernogeneralpib 